\title{
Research on the Growth Capacity of the Real Estate Business
}

\author{
Linjie Chen \\ Department of Business Administration, Nanjing Institute of Industry Technology \\ Nanjing 210046, China \\ E-mail:ngy001@163.com
}

\begin{abstract}
Foundation item: Supported by Department of Education Jiangsu Province. (No. 2010SJB630034)
Supported by Nanjing Institute of Industry Technology (No. YK10-05-01)
\end{abstract}

\begin{abstract}
This paper analyzes the connotation of growth capacity in real estate enterprises in reviewing the relevant theoretical literature, builds its identification model from three angles and evaluation model by fuzzy theory from three dimensions, and finds the growth capacity of Vanke Group as an example to, come in a "strong" rating through the identification and evaluation. The model can be used in other industries to identify and evaluate growth capacity.
\end{abstract}

Keywords: Real estate enterprises, Growth capacity, Identification model, Evaluation model

Growth capacity is the basis for sustained growth and the source of lasting competitive advantage of real estate enterprises,it plays a fundamental role in identifying market opportunities, enhance quality, against market risks, adapting to environmental change. Identification and evaluation is a prerequisite for the further improvement and development such capacity.

\section{The identification and evaluation theoretical basis for the growth capacity of enterprises}

\subsection{The concept of growth capacity}

Enterprises Growth theory come from the " The theory of the Growth of the Firm " book published by Penrose (Penrose, 1959), Penrose believes that the growth of enterprises may be explained under this framework of the "enterprise resource - the capacity of enterprises - enterprises growth". Dynamic capabilities of the enterprise is its needs of survival and growth, is an process which an enterprise to avoid being eliminated,take the initiative to "adapt" to external risks and to achieve "the capacity of evolution" (Gu Xingshu, 2009, pp.45-47). Teece and others believe that the dynamic capability is the long-established business organizations learn, adapt and change. That is, to maintain or change its competitive advantage as the basis of capacity(Teece D., Pisano G. \&Shuen A., 1997,pp.509-533). Generally speaking, the growth capacity of enterprises refer to enterprises in a dynamic environment always the potential of life and energy, is the accumulated knowledge and skills in the dynamic evolution, which determines the path of growth and spatial and temporal boundaries. The growth of enterprises includ volume growth and quality growth,which is the dialectical unity, is the dialectical unity of quantity and quality.

\subsection{The connotation of the growth capacity of the real estate business}

At present, domestic and foreign research on the growth capacity of real estate enterprises identification and evaluation is obviously inadequate. In accordance with the concept of growth capacity, the connotation of the growth capacity of the real estate business is that it have accumulated, integrated and effective use of internal and external resources to identify and develop the real estate market, improve the quality of land planning, technological innovation, quality and value of housing, as well as improve the efficiency of enterprise management, so that the real estate business was healthy, preface, continued to grow and develop. The growth capacity of the real estate enterprises including capital, land resources, human resources, innovation, marketing and management capacity, etc; It comes from the human resources, capital, products, customer service and brand elements; It is mainly reflected in the market, quality and products, that is reflected in the market to grasp, quality control, product design, product innovation, such as on.

\section{Identification of the growth capacity of the real estate business}

\subsection{The identification model of the growth capacity of the real estate business}

Guo Rui analysis the main variables of corporate sustainable growth from the five dimensions of the social 
environment, industry, technology, systems and finance, emphasis on the integration of the five dimensions of the system deciding the capacity of sustainable growth (Guo Rui, 2005, pp.79-83). According to the theoretical study of the growth capacity, the connotation of the real estate business growth capacity and the actual situation of China's real estate business,three-dimensional method used here from product and market profitability (performance capacity), organizations operating both inside and outside resources (basic capacity), organizational development (potential capacity) to build the growth capacity identification model of the real estate business, see Figure (1). Sustainable growth capacity of the real estate business can be described as: $Y=f$ (performance capacity, basic capability, potential capacity). The performance capacity of the real estate business can be identified from the perspective of products and markets; The basic capacity of the real estate business can be identified from the perspective of internal and external resources operating; The potential capacity of the real estate business can be identified from the perspective of the future development of the organization.

\section{Insert figure 1 here}

\subsection{The evaluation index system of the growth capacity of the real estate business}

The continued growth capacity of Hines American company can be attributed to three major principles: the quality development capacity, learning and innovation capacity and people-oriented management capabilities(Wang Hongwei,Ren RongWei \& Song Li.2007, pp.32-33). The continued growth capacity of China's real estate business can be described as the performance capacity, basic capacity and the potential capacity,here builds its analysis and evaluation index system from the three aspects,as shown in table (1) and figure (2). The Growth capacity of the real estate business evaluation system has been broken down the main indicators and sub-indicators based on two levels, the main indicators includes performance indicators, the basic indicators and potential indicators of the three types of capacity, a total of 12 sub-indicators.

\section{Insert table 1 here}

\section{Insert figure 2 here}

\section{Evaluation of the growth capacity of the real estate business}

At present, domestic and foreign studies about the concept and composition of the growth capacity of real estate enterprises is very few, the existing literature has not specifically research on the identification and evaluation model for the growth capacity of the real estate enterprises.By FUZZY theory the subject builds the evaluation model of the growth capacity of the real estate business from China's actual situation, in accordance with the principles of convenience for enterprises operating.

\subsection{Evaluation factors into FUZZY}

As it is difficult to obtain precise numerical of evaluation index, the experience judge of industry experts, professors and practitioners is used for comprehensive evaluation. Experience judge into the value of FUZZY language to replace the numerical computation, it can also achieve very high accuracy rating evaluation. In order to facilitate the use of, this case only seven minutes to quantify the value of language. The use of seven FUZZY followed by the number of 1,2,3,4,5,6,7 said [VL] (very low), [L] (low), [RL] (rather low), [M] (not high nor low), $[\mathrm{RH}]$ (rather high), $[\mathrm{H}]$ (high), $[\mathrm{VH}]$ (very high), as well as the situation of the growth capacity of seven level $[\mathrm{VW}]$ (very weak),[W](weak), $[\mathrm{RW}]$ (rather weak),[M](general), [RS] (rather strong), [S](strong),[VS] (very strong).

Based on the domain $U=[0,5]$, the $U$ can be defined in the $[\mathrm{VL}],[\mathrm{L}],[\mathrm{RL}],[\mathrm{M}],[\mathrm{RH}],[\mathrm{H}],[\mathrm{VH}]$ language value, by the formula

$\mathrm{Be}$

$$
\mathrm{A}=\int \mathrm{U}\left[\mu_{\mathrm{A}}(\mathrm{u}) / \mathrm{u}\right]
$$

$$
\begin{aligned}
& {[\mathrm{VL}]=0.8 / 0+1 / 0.001+0.8 / 0.002+0.3 / 0.003+0.1 / 0.004} \\
& {[\mathrm{~L}]=0.8 / 0+1 / 0.005+0.8 / 0.01+0.3 / 0.015+0.1 / 0.02} \\
& {[\mathrm{RL}]=0.8 / 0+1 / 0.01+0.8 / 0.02+0.3 / 0.03+0.1 / 0.04} \\
& {[\mathrm{M}]=0.8 / 0+1 / 0.05+0.8 / 0.1+0.3 / 0.15+0.1 / 0.2} \\
& {[\mathrm{RH}]=0.8 / 0+1 / 0.1+0.8 / 0.2+0.3 / 0.3+0.1 / 0.4} \\
& {[\mathrm{H}]=0.8 / 0+1 / 0.5+0.8 / 1+0.3 / 1.5+0.1 / 2.0} \\
& {[\mathrm{VH}]=0.8 / 0+1 / 1.0+0.8 / 2+0.3 / 3.0+0.1 / 4.0}
\end{aligned}
$$

Similarly, is the availability status of the growth capacity of seven grades [VW], [W], [RW], [M], [RS], [S], [VS] language value. 


\subsection{FUZZY evaluation model}

FUZZY evaluation is a very complicated calculation, in order to facilitate evaluation, here FUZZY sets of type II by M.Mizumoto and K.Tauaka is used (Shuibenyaqin,1986,pp.47-59), it can give full consideration to the information FUZZY language.

If $\mathrm{A}$ there are $\mathrm{n}$ basic evaluation elements indicators, then

Formula

$$
\mathrm{A}^{(2)}=\sum_{\mathbf{i}=\mathbf{1}}^{\mathbf{n}} \alpha \mathbf{i} / \mathrm{Wi}
$$

Wi- the first i elements indicators;

$\alpha i-\mathrm{Wi}$ element indicator to the growth capacity the extent of the impact.

If the expression vector, then

$$
\begin{array}{cc} 
& \mathrm{A}^{(2)}=\alpha^{(2)}=\left(\alpha_{1}, \alpha_{2}, \ldots, \alpha \mathrm{\alpha n}\right) \\
\text { Similarly } & \mathrm{B}^{(2)}=\beta^{(2)}=\left(\beta_{1}, \beta_{2}, \ldots, \beta \mathrm{m}\right) \\
& \mathrm{C}^{(2)}=\gamma^{(2)}=\left(\gamma_{1}, \gamma_{2}, \ldots, \gamma \mathrm{m}\right)
\end{array}
$$

Set $\quad \mathrm{A}^{(2)}, \mathrm{B}^{(2)}, \mathrm{C}^{(2)}$ is on the domain $\mathrm{U}$ of type II FUZZY set, their " $\cap$ " operation is:

$$
\begin{array}{r}
\left(\mathrm{A}^{(2)} \cap \underline{B}^{(2)}\right)(\mathrm{u})=\mathrm{A}^{(2)}(\mathrm{u}) \wedge \mathrm{B}^{(2)}(\mathrm{u})=\alpha^{(2)} \wedge \beta^{(2)} \\
\alpha^{(2)} \wedge \beta^{(2)}=\left(\quad{ }_{\mathrm{i}=\mathbf{1}}^{\mathrm{m}} \alpha_{1} \wedge \mathrm{Bi}, \quad \underset{\mathrm{i}=\mathbf{1}}{\vee} \alpha_{2} \wedge \mathrm{Bi}, \ldots, \underset{\mathrm{m}=\mathbf{m}}{\vee} \alpha_{\mathrm{n}} \wedge \mathrm{Bi}\right)
\end{array}
$$

Set $\quad \alpha, \beta$ is the value of FUZZY language, then

$$
\sum_{\mathbf{i}=1}^{\mathbf{n}} \alpha+\beta=\{\quad(\alpha \mathrm{i} \wedge \beta \mathrm{i} / \mathrm{i})\} / 2
$$

Similarly, the value of the FUZZY language $\alpha+\beta+\gamma$ of $\left[\left(\mathrm{A}^{(2)} \cap \mathrm{B}^{(2)}\right)(\mathrm{u})\right] \cap \mathrm{C}^{(2)}(\mathrm{u})$ can be calculated.

Through this formula, you can come to a final evaluation information $\mathrm{M}$ of the growth capacity of an enterprise. For the information value of $\mathrm{M}$,which can be judged the situation of its growth capacity in the seven levels ([VW], [W], [RW], [M], [RS], [S], [VS]) with which one level the same or similar, FUZZY pattern recognition is used here.

Set $\mathrm{M}, \mathrm{Mi} \in \mathrm{F}(\mathrm{V}),(\mathrm{i}=1,2, \ldots, 7)$, If there is a level $\mathrm{j} \in(1,2, \ldots, 7)$, resulting in

$$
\mathrm{N}(\mathrm{M}, \mathrm{Mj})=\operatorname{MAX}\{\mathrm{N}(\mathrm{M}, \mathrm{Mi})\}
$$

Well, the most similar to $\mathrm{M}$ and $\mathrm{Mj}$, and $\mathrm{M}$ is found at this level $\mathrm{Mj}$. Which $\mathrm{N}(\mathrm{M}, \mathrm{Mj})$ is close to, the formula for

$$
\mathrm{N}(\mathrm{M}, \mathrm{Mj})=\{\mathrm{M} \oplus \mathrm{Mj}+(1-\mathrm{M} \odot \mathrm{Mj})\} / 2
$$

4. The empirical application and analysis of identification and evaluation model of the business growth capacity: A case study in Vanke groupas

\subsection{Vanke Group, the basic situation introduction}

Vanke Group was founded in May 1984, is China's largest residential developer. Vanke stock market 18 years ago, the main business income compound growth rate of $28.3 \%$, net profit compound growth rate of $34.1 \%$, is listed after the longest period of sustained profit growth of Chinese enterprises.It was selected twice by Forbes "Best Small Business",and many times the best corporate governance and best investor relations awards and others by the international authority media such as the "Investor Relations", "Asian currencies," and others in the development process. Vanke general course of development can be divided into three phases: 1984 -1992 was the first phase (Diversification phase), which from 1984 to 1988 is the start-up phase;1992 -2001 was the second phase (operating stage of specialization), as a dedicated real estate company;So far in 2002 is the third phase of development Vanke (operation refinement). (Vanke http://sh.vanke.com company's Web site) .

\subsection{The growth capacity identification to Vanke Group}

Vanke Group, started trading in 1984, can be gradually developed into the first Chinese real estate enterprise, its success is no accident. Vanke's success stems from the growth capacity. What then is the Vanke's growth capacity? To be here for the purpose of identifying, according to Figure (1) model and Table (1) indicators, it's 
source is identified detail from the perspective of three. Based on the identification of growth capacity, we can draw a set of empirical judgment about Vanke's growth capacity. These experiences come from the representation of some real estate industry experts, operators and employees, as shown in table (2), the table index value of FUZZY language refers to the impact of Vanke's growth capacity. By FUZZY evaluation model, you can evaluate the current growth capacity of Vanke Group and obtain the results.

\section{Insert table 2 here}

\subsection{The growth capacity evaluation to Vanke Group}

By the formula (3-3), (3-4), (3-5), you can calculate \{Performance capacity indicators\}, \{Basic capacity indicators and $\{$ Potential capacity indicators $\}$ there type II FUZZY sets $\mathrm{A}^{(2)}, \mathrm{B}^{(2)}, \mathrm{C}^{(2)}$; By the formula (3-6) (3-8), the final FUZZY information can be calculated:

$$
\mathrm{M}=0.8 / 0+1 / 0.621+0.8 / 1.242+0.3 / 1.843+0.1 / 2.464
$$

Then according to formula (3-9) - (3-10), is:

$$
\begin{array}{r}
\mathrm{N}\{\mathrm{M},[\mathrm{RW}]\}=\operatorname{MAX}\{-0.210,-0.049,-0.010,0.051,0.347, \mathbf{0 . 5 9 7}, 0.156\} \\
\{[\mathrm{VW}], \quad[\mathrm{W}],[\mathrm{RW}],[\mathrm{M}],[\mathrm{RS}],[\mathrm{S}],[\mathrm{VS}]\}
\end{array}
$$

From the above results, Vanke's growth capacity is in the $[\mathrm{S}]$, that is "strong" state.

The growth performance of "strong" is a major factor in the capacity of Vanke Group's excellent performance, that is, the ability to grasp very well the industry, expanding market awareness very well, product planning and design capabilities very well and ability to develop excellent quality, financial strength and strong land auction;The basic ability to down-to-earth, that is, number one Wang's leadership ability strong, professional strategy, resource integration, the internal structure of the system response capacity in place;Sufficient potential capacity, that is, "Building an unlimited life, health life," the values and operating philosophy bearing in mind of the the staff, employees actively learning and innovation,very capable personnel.Vanke Group, the future need to strengthen is to increase R\&D capacity, continue to strengthen the capacity of doing the accumulation of tacit knowledge, and more to learn from foreign real estate enterprises, so that further refinement of real estate development, specialization, and achieve the growth capacity "a strong " state, as soon as possible from the domestic first-class real estate business into a world-class one.

\section{Conclusion}

(1) From three dimensions to build the evaluation model of growth capacity of the real estate business by the FUZZY theory, Vanke Group, in an example, obtained the capacity to grow at a "strong" rating through the identification and evaluation.

(2) The empirical application shows that the results of the FUZZY evaluation model is realistic, and this method is practical,it solved the non-quantitative data to evaluate business growth challenges, have greater practical value. The model can be used for the other industries and enterprises to identify and evaluate growth capacity,it has important reference value for enterprises to formulate development strategies and operational decision-making.

(3) The identification and evaluation of growth capacity can help enterprises to further improve and develop such capacity. The use of the identification and evaluation model to evaluate the growth of enterprises, the main reasons in strong or weak growth capacity of some enterprises in China can be found, easy to take measures accordingly.

\section{References}

$\mathrm{Gu}$, Xingshu. (2009). Business growth research - based on the dynamic capabilities match with the outside perspective of strategic risk. Modern management scienc, (3): 45-47

Guo Rui. (2005). The Content and the Evaluation Methods of the Corporate Sustainable Growth Ability. Soft Science. (6):79-83

Penrose, Edith. T. (1959). The theory of the Growth of the Firm. Newyork, JohnWiley.

Shuibenyaqin (Japan). (1986). Fuzzy Mathematics and Its Applications. Beijing: Science Press. 47-59

Teece D., Pisano G., \& Shuen A. (1997). Dynamic Capabilities and Strategic Management. Strategic Management Journal, 18(7):509-533. 
Wang, Hongwei, Ren, Rongwei \& Song Li. (2007). The analysis of growth ability factors in The United States real estate development enterprises - based on the heterogeneity of enterprise resource perspective. Modern management science, (2):32-33

Vanke http://sh.vanke.com company's Web site

Table 1 . The growth capacity indicatorss of the real estate business

\begin{tabular}{c|c|l}
$\begin{array}{c}\text { Capacity } \\
\text { level }\end{array}$ & Object & \multicolumn{1}{c}{ Capacity type } \\
\hline $\begin{array}{c}\text { Performance } \\
\text { capacity }\end{array}$ & $\begin{array}{c}\text { Product and } \\
\text { market } \\
\text { profitability }\end{array}$ & $\begin{array}{l}\text { Business development capacities: the ability to grasp the } \\
\text { industry (vision, cycle, the environment, policy-aware), } \\
\text { marketing knowledge expand capacity (to grasp the } \\
\text { opportunity, marketing planning, the operation of the market), } \\
\text { product planning and design capabilities, quality development } \\
\text { capacity, the capacity of capital and land auction }\end{array}$ \\
\hline $\begin{array}{c}\text { Basic } \\
\text { capacity }\end{array}$ & $\begin{array}{c}\text { Organizations } \\
\text { operating both } \\
\text { inside and } \\
\text { outside resources }\end{array}$ & $\begin{array}{l}\text { Support the organization and management capabilities: } \\
\text { entrepreneurial leadership, development of adaptation } \\
\text { strategies (positioning, product selection, development mode), } \\
\text { ability to integrate resources (human resources, land, etc.), the } \\
\text { internal structure of the system response capabilities } \\
\text { (organization, systems, quality, costs, brands, services) }\end{array}$ \\
\hline $\begin{array}{c}\text { Potential } \\
\text { capacity }\end{array}$ & $\begin{array}{c}\text { The future } \\
\text { development }\end{array}$ & $\begin{array}{l}\text { Cultural learning innovation capability: values and } \\
\text { management philosophy, innovation and learning capacity, the } \\
\text { quantity and quality of talen }\end{array}$ \\
\hline
\end{tabular}

Table 2. The empirical evaluation of the growth capacity of Vanke Group

\begin{tabular}{|c|c|c|c|}
\hline Order & $\begin{array}{l}\text { Capacity } \\
\text { level }\end{array}$ & $\begin{array}{l}\text { Evaluation indicator of growth } \\
\text { capacit }\end{array}$ & $\begin{array}{l}\text { The extent of } \\
\text { the impact } \\
\text { (experience) }\end{array}$ \\
\hline 1 & \multirow{5}{*}{$\begin{array}{l}\text { Performance } \\
\text { capacity }\end{array}$} & The ability to grasp the industry & {$[\mathrm{H}]$} \\
\hline 2 & & $\begin{array}{l}\text { Marketing knowledge expand } \\
\text { capacity }\end{array}$ & {$[\mathrm{H}]$} \\
\hline 3 & & $\begin{array}{l}\text { Product planning and design } \\
\text { capabilities }\end{array}$ & {$[\mathrm{H}]$} \\
\hline 4 & & Quality development capacity & {$[\mathrm{RH}]$} \\
\hline 5 & & $\begin{array}{l}\text { The capacity of capital and land } \\
\text { auction }\end{array}$ & {$[\mathrm{VH}]$} \\
\hline 6 & \multirow{4}{*}{$\begin{array}{l}\text { Basic } \\
\text { capacity }\end{array}$} & Entrepreneurial leadership & {$[\mathrm{H}]$} \\
\hline 7 & & Development of adaptation strategies & {$[\mathrm{RH}]$} \\
\hline 8 & & Ability to integrate resources & [VH] \\
\hline 9 & & $\begin{array}{l}\text { The internal structure of the system } \\
\text { response capabilities }\end{array}$ & {$[\mathrm{M}]$} \\
\hline 10 & \multirow{3}{*}{$\begin{array}{l}\text { Potential } \\
\text { capacity }\end{array}$} & Values and management philosophy & {$[\mathrm{RH}]$} \\
\hline 11 & & Innovation and learning capacity & {$[\mathrm{H}]$} \\
\hline 12 & & The quantity and quality of talen & {$[\mathrm{H}]$} \\
\hline
\end{tabular}




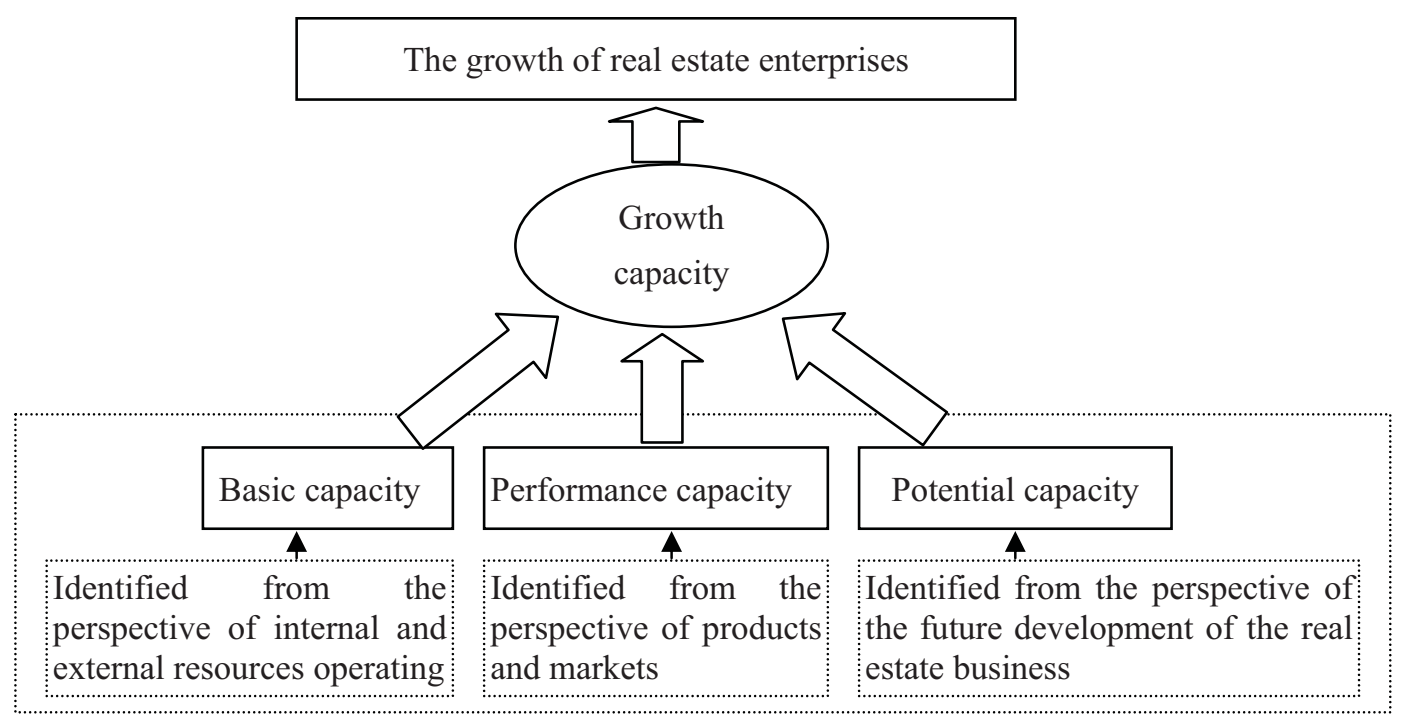

Figure 1. The identification model of the growth capacity of the real estate business

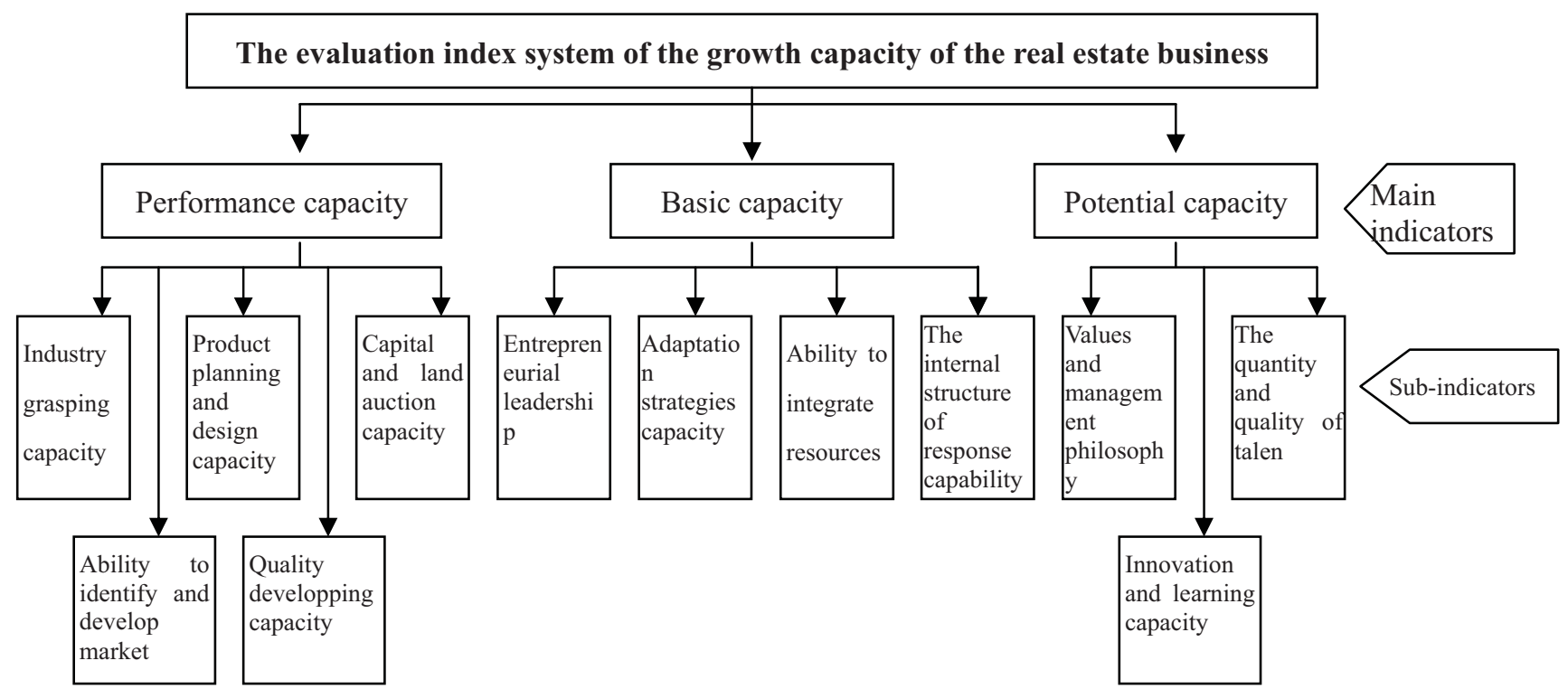

Figure 2. The evaluation index system of the growth capacity of the real estate business 